\title{
INFLUENCE OF LIGHTNING ON OPERATION OF RAILWAY TRANSPORT DEVICES
}

\author{
Nikolay Klimov \\ Federal State Budgetary Educational Institution "Irkutsk \\ State Transport University" \\ (FSBEI HE ISTU) \\ Irkutsk, the Russian Federation \\ klinn@irgups.ru
}

\section{Sergey Cheremisin}

Irkutsk Communications Directorate Directorate of the Central Communications Office of the branch of OAO Russian Railways

Irkutsk, the Russian Federation

cheremisin@irk.esrr.ru

\author{
Sergey Kutsenko \\ Federal State Budgetary Educational Institution "Irkutsk \\ State Transport University" \\ (FSBEI HE ISTU) \\ Irkutsk, the Russian Federation \\ kutsenko_s@irgups.ru \\ Sergey Shurygin \\ Irkutsk Communications Directorate Directorate of the \\ Central Communications Office of the branch of OAO \\ Russian Railways \\ Irkutsk, the Russian Federation \\ dasip@irk.esrr.ru
}

\begin{abstract}
The article briefly discusses the general mechanisms for the occurrence of lightning. Based on satellite data, the total number of lightning on the East Siberian Railway (ESR) in the summer is estimated.
\end{abstract}

Keywords-thunderstorm cloud formation mechanisms, lightning discharge generation mechanisms, magnitude of the lightning discharge currents, electric field strength in the cloud, number of failures due to lightning.

\section{INTRODUCTION}

Lightning, one of such phenomena observed in Siberia, occurs usually in the summer months and is one of the natural factors that sometimes disables the railway infrastructure of OAO Russian Railways, for example, such as automation, telemechanics and communications lines.

The impact of lightning (herein - a storm discharge between the cloud and the ground) is manifested at the railways of the Siberian region, more often in the Transbaikalian region. As follows from the document "Analysis of the state of the safety of the operation of systems and devices of the railway automatics and telemechanics (RAT) in the economy of automation and telemechanics in 2011" (p.119), the number of failures of the RAT devices under the influence of lightning discharges at the East Siberian Railway (ESR) in 2010 is 44, and in 2011 is 46. As for the Trans-Baikal railway, their number is 150 in 2010 and is 140 in 2011. This is due to the fact that there are sites of permafrost along the Trans-Baikal Railway route. When lightning strikes the ground, even at a distance of 100-300 meters, there might be a breakdown in the insulation of the cables which are laid along the track. The underlying substrate from the permafrost layer does not allow local leakage of lightning current into the ground, and the current flowing horizontally results in a breakdown of the cable insulation. Therefore, it is of interest to consider modern views of the influence of lightning on the operation of railway infrastructure facilities.

\section{ABOUT THE FORMATION OF LIGHTNING AND ITS IMPACT ON THE OBJECTS OF RAILWAY INFRASTRUCTURE}

Electrical phenomena in the atmosphere are extremely interesting and are still not completely clear. To begin with, the ground surface has a negative charge relative to the upper conducting layers of the atmosphere (IONOSPHERE). The strength of the vertical component of this field near the surface is approximately $100-150 \mathrm{~V} / \mathrm{m}$. The total potential difference between the ground and the ionosphere is $300-400 \mathrm{kV}$, the current value is a few $10-12 \mathrm{~A} / \mathrm{m} 2$. This corresponds to a power of 600-700 MW for the total current for the whole Earth! If there was no constant supply of this potential difference, after about half an hour the negative charge of the Earth disappeared [1].

The current flowing between the Earth and the ionosphere changes around the world time per day by about $\pm 15 \%$ and has a maximum of 19 hours of world time, and at least 4 hours, regardless of the place of observation. Accordingly, the potential gradient changes with this: over the ocean, when the weather is clear, from about $90 \mathrm{~V} / \mathrm{m}$ at a minimum to $115 \mathrm{~V} / \mathrm{m}$ at the maximum. For a long time, the reason for this was mysterious. It is now established that such a source is the lightning, which acts as the generator during a thunderstorm that simultaneously charges the Earth and high conducting layers of the atmosphere. According to modern ideas, the reason for the variation in the potential difference is the change in the number of thunderstorms with the world time. Until the middle of the 20th century it was believed that the maximum number of thunderstorms falls on that part of the globe when the Sun illuminates the Pacific Ocean. The latest 
studies of the number of lightning flares on the Earth, carried out on the satellite, are shown in Fig. 1, taken from [2].

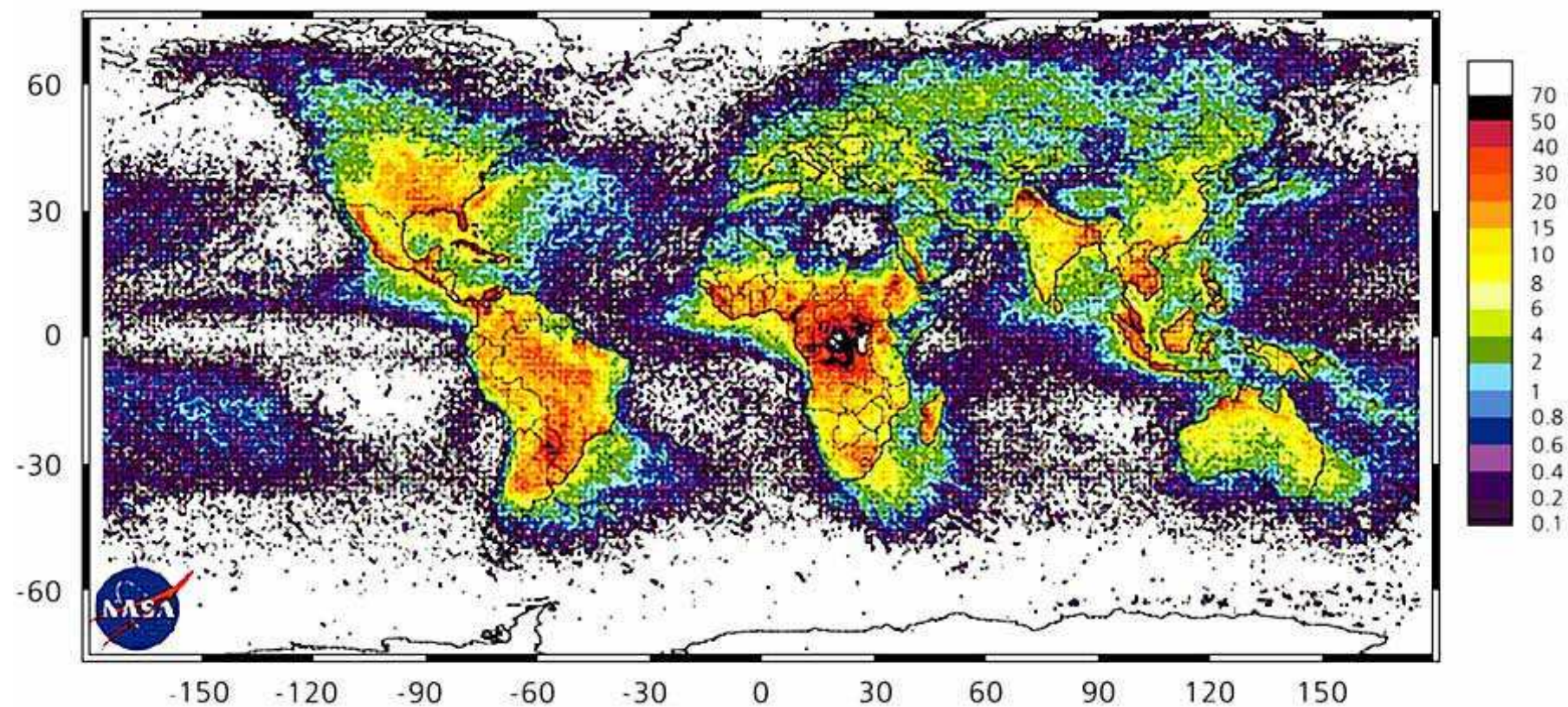

Fig. 1. Distribution of lightning flares on the surface of the globe. The results of optical observations from the OTD and LIS satellites (By: Christian H.J., et al., J. Geophys, Res., 2003. V.108 (D1); doi: 10.1029 / 2002JD002347).

Figure 2 shows that the main thunderstorm foci are located above the continents in the 30 -degree latitude range relative to the equator. On the right there is a color scale of the number of lightning strokes per square kilometer per year. From these data it follows that the average annual frequency of flashes does not exceed 46 per second. At the Siberian territory the number of lightning strikes per year does not exceed 2-4 $\mathrm{km} 2 /$ year. If it is assumed that lightning strikes can damage railway infrastructure within a 30-meter range, the number of such cases on the East-Siberian Railway may reach 300-600 per year.

Theoretical conclusions obtained in the early 2000s at the Institute of Applied Physics in Nizhny Novgorod estimate the power in a global electric circuit (GEC) being of $4 \bullet 1011 \mathrm{~W}$, i.e. $4 \bullet 105 \mathrm{MW}[2]$. The authors associate this with mediumscale (about $100 \mathrm{~km}$ ) processes in the atmosphere, which are also generators. The scheme of the GEC is shown in Fig. 2, which is taken from [2]. It is the authors' opinion that the main generators of electrical energy are mesoscale charge separation structures, which ensure that the feed currents of the GEC are of the order of 1 million amperes! They are shown on the left of the diagram.

After the distribution of charges is formed in the cloud, a large voltage between the cloud and the ground results in a breakdown of this gap. First, a stepped leader appears, which runs a weakly luminous conducting channel along the path of least resistance [3-5]. It is immediately followed by a bright return stroke that follows from the ground to the cloud. After a while, if the conducting channel has not disappeared, the dart leader passage might occur. Conductive channels that form these objects lead to the discharge of a thunderstorm cloud, the generation of thunder and electromagnetic radiation. The average propagation velocity of the formations is $1,5 \times 105 \mathrm{~m} / \mathrm{s}$, $5,0 \times 107 \mathrm{~m} / \mathrm{s}$ and $2,0 \times 106 \mathrm{~m} / \mathrm{s}$, respectively. A sufficiently complete quantitative theory of the formation of these objects to date does not yet exist. The application of the theory of a spark discharge and an arc explains the observed characteristics of lightning at a semiquantitative level [3-5]. 


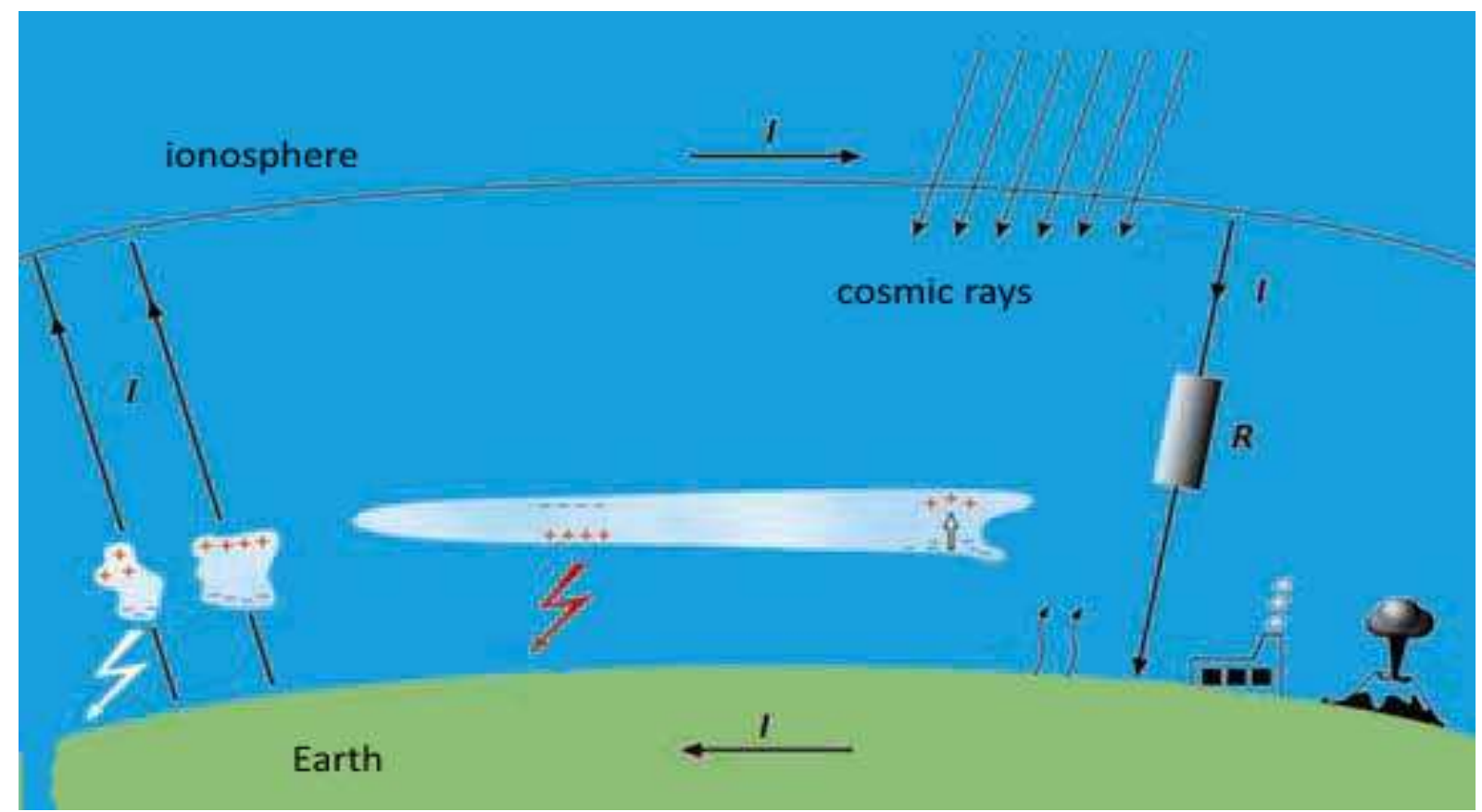

Fig.2. Schematic representation of the global atmospheric electric circuit

Observations of discharge phenomena in the middle atmosphere with the help of artificial Earth satellites (AES) made it possible to register such new phenomena, correlating with thunderstorm activity, as sprites (areas of luminescence that are visible from the altitudes of $40-55 \mathrm{~km}$ to $85-90 \mathrm{~km}$ above ground for intervals of time from units to tens of milliseconds, elves (the altitudes are $70-90 \mathrm{~km}$, duration is less than 100 microseconds) and jets (discharges starting at the top of the cloud and spreading sometimes to mesospheric altitudes $(70-90 \mathrm{~km})$ at a speed of about $100 \mathrm{~km} / \mathrm{s})[2,6]$.

Along with lightning discharges directed to the ionosphere, bursts of gamma, X-ray and ultraviolet radiation correlated with thunderstorm activity were observed [2]. The maximum gamma radiation energies registered in the spectrum at the AES were $1 \mathrm{MeV}$ or more; the $\mathrm{x}$-ray emission on the balloons had a maximum in the energy range $50-60 \mathrm{keV}$ and duration of the order of a minute. Surface observations also revealed intense X-ray flashes with a quantum energy of several hundred $\mathrm{keV}$, the emergence of which correlated with the formation of the leader of the lightning flash and the dart leader of the trigger lightning (lightning caused by an rocket with a wire artificially launched to a thunderstorm cloud).

In recent years, large-scale measures have been taken at the objects of the railway infrastructure to protect the devices from lightning strikes [7, 8]. Nevertheless, the problem of lightning discharge protection of devices, buildings, structures of railway automation facilities, telemechanics and communications is still extremely urgent.

\section{COMPARISON OF THE NUMBER OF OBSERVED LIGHTNING WITH THE NUMBER OF FAILURES AT THE EAST SIBERIAN RAILWAY}

As follows from the above, the number of lightning strikes in the 30-meter range along the East Siberian Railway should be about 500. At the same time, as follows from the analysis of failures of the signalling, centralization and blocking (SCB) devices on the East-Siberian Railway, conducted by the Automation and Remote Control Service, since 2007 to 2013 decreased from 70 to 26 due to the installation of 2219 surge overvoltage protection (lightning discharge protection) devices UZP1-500 during the same period [9].

Along with this number of failures of the signaling devices because of the lightning, additional power supply failures in the amount of 30 are added [10]. During a thunderstorm front passage, there might be disruptions in the operation of the signaling and power supply devices sequentially at several sections of the road. For example: during the passage of a thunderstorm front at the Utulik-Andrianovskaya section on the day of June 23, 2014 of the Slyudyanskaya division of the Signalling, Centralization and Blocking of the East-Siberian Directorate of Infrastructure (Division of Signalling and Communication-7), the failures of the signaling devices were recorded in the period from 20:47 to $23: 40$ at 4 sections with a failure of $2 \mathrm{BV}$ (rectifier unit) blocks, light-out small-sized relay OMSh2-46, normal operating relay NMSh2-900, relay boards NMSH, boards of blocks of track receivers of tonal rail

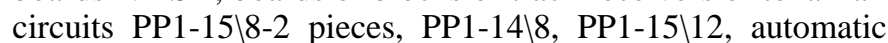
switches AVM (3 pcs.), 6-kV power cable and 23 fuses [11].

Thus, the recorded number of failures during the passage of the thunderstorm fronts in the absence of protection (2007) 
does not exceed 100. This is almost 5 times less than the registered number of lightning in the 30-meter range along the East Siberian Railway. In our opinion, this is due to the fact that only sufficiently powerful lightning has a significant influence on the operation of the signaling and power supply devices up to their failure. According to the estimates given in [12], the total probability of lightning strikes with a current value in the range of 50-150 kA does not exceed 0.25 . Such probability of lightning with a high current reduces their number to about 100 , which corresponds to the number of failures on the East Siberian Railway associated with thunderstorm activity [9-11].

\section{CONCLUSION}

As follows from the above, the number of lightning strikes in the 30-meter range along the East Siberian Railway should be about 500. At the same time, as follows from the analysis of failures of the signalling, centralization and blocking (SCB) devices on the East-Siberian Railway, conducted by the Automation and Remote Control Service, since 2007 to 2013 decreased from 70 to 26 due to the installation of 2219 surge overvoltage protection (lightning discharge protection) devices UZP1-500 during the same period [9].

Along with this number of failures of the signaling devices because of the lightning, additional power supply failures in the amount of 30 are added [10]. During a thunderstorm front passage, there might be disruptions in the operation of the signaling and power supply devices sequentially at several sections of the road. For example: during the passage of a thunderstorm front at the Utulik-Andrianovskaya section on the day of June 23, 2014 of the Slyudyanskaya division of the Signalling, Centralization and Blocking of the East-Siberian Directorate of Infrastructure (Division of Signalling and Communication-7), the failures of the signaling devices were recorded in the period from 20:47 to $23: 40$ at 4 sections with a failure of $2 \mathrm{BV}$ (rectifier unit) blocks, light-out small-sized relay OMSh2-46, normal operating relay NMSh2-900, relay boards NMSH, boards of blocks of track receivers of tonal rail

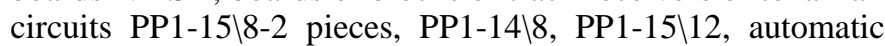
switches AVM (3 pcs.), 6-kV power cable and 23 fuses $[11,12]$.

Thus, the recorded number of failures during the passage of the thunderstorm fronts in the absence of protection (2007) does not exceed 100. This is almost 5 times less than the registered number of lightning in the 30-meter range along the East Siberian Railway. In our opinion, this is due to the fact that only sufficiently powerful lightning has a significant influence on the operation of the signaling and power supply devices up to their failure. According to the estimates given in [12], the total probability of lightning strikes with a current value in the range of 50-150 kA does not exceed 0.25. Such probability of lightning with a high current reduces their number to about 100 , which corresponds to the number of failures on the East Siberian Railway associated with thunderstorm activity [9-12].

\section{Acknowledgment}

The authors are grateful to the head of the laboratory of the Irkutsk Communications Directorate Igor Vladimirovich Antsiferov, the engineer of the production and technical department of the East Siberian infrastructure director Vasiliy Vyacheslavovich Bichevin for assistance in collecting data on the failures of the ESR infrastructure due to thunderstorms.

\section{References}

[1] R. Feyman, R. Layton, M. Sands Feyman's lectures on physics. Vol.5. Electricity and magnetism. Moscow: Mir Publ., 1966, Chapter 9, pp.172-195

[2] E.A. Mareev, V.I. "Trakhtengerts Mysteries of atmospheric electricity", Priroda, No.3, p.24-33, 2007.

[3] M. Yuman Lightning. Moscow: Mir Publ., 1972, 327 p.

[4] E.M. Bazelyan, Yu.P. Raizman Spark discharge. Moscow: Moscow Institute of Physics and Technology Publ., 1997, 320 p.

[5] E.M. Bazelyan, Yu.P. Raizman Physics of lightning and lightning protection. Moscow: FIZMATLIT Publ., 2001, 320 p.

[6] W.A. Lyons "The meteorology of transient luminous events-an introduction and overview. In: Fullekrug, M., et al. (Eds.), NATO Advanced Study Institute on Sprites, Elves and Intense Lightning Discharges", Springer, Dordrecht, The Netherlands, pp. 19 - 56, 2006.

[7] Rail infrastructure devices. Protection against atmospheric and switching overvoltage. Lightning protection and grounding devices for technical facilities. Technical requirements. The standard of OAO Russian Railways. 08-026 2015.

[8] Instruction on the installation of lightning protection of buildings, structures and industrial communications. Approved by the Order 280 of the Ministry of Energy of the Russian Federation, 2003.

[9] Report on the TTS "Protection of security-related devices from weathering conditions", 2014 "Protection of security devices in the border of the North Baikal region from lightning effects". 2015 East Siberian Directorate of Infrastructure. Automation and telemechanics service. Deputy Head A.N. Nepomnyashchikh. Irkutsk, Administration of the East Siberian Railway.

[10] Data from the ACS SH-2 KZALSN of ESR dated 2014.

[11] Information about the passage of the thunderstorm front at the UtulikAndrianovskaya site in the days of June 23, 2014 of the Slyudyanskaya distance of the SCB ESDI (Division of Signalling and Communication7). Prepared by Serova TA. Direction of the infrastructure of the Eastern Railway. (Prepared specifically at the request of the authors).

[12] M.M. Rezinkina "Method for calculating the predicted number of lesions by lightning of long objects", ZhTF, Volume 78, Issue 5, pp. 1-7, 2008 . 